\title{
Suplementação concentrada para cordeiros terminados a pasto sobre custo de produção no período da seca
}

\section{Concentrate supplementation in lambs finished at pasture on cost of production in the dry season}

\author{
Luiz Juliano Valério Geron ${ }^{1 *}$; Alexandre Agostinho Mexia ${ }^{1}$; Jocilaine Garcia ${ }^{1}$; \\ Marciano Moreira da Silva²; Lúcia Maria Zeoula ${ }^{3}$
}

Resumo

\begin{abstract}
Objetivou-se avaliar os níveis de suplementação concentrada $(0,0 \% ; 0,5 \% ; 1,0 \%$ e $1,5 \%$ do peso corporal - PC) constituída de caroço de algodão com grão de milho moído (CAGM) na proporção de 50\% cada, em cordeiros terminados a pasto (Capim Marandu) abatidos com 31,7 kg de PC, sobre ganho médio diário (GMD), dias de suplementação (DS) e custo de produção no período da seca. Foram utilizados 20 cordeiros sem raça definida com PC inicial de $19 \pm 0,5 \mathrm{~kg}$ distribuídos em quatro tratamentos. A suplementação de CAGM foi fornecida em baias separadas por nível de suplementação diariamente as dezoito horas. Foi utilizado um delineamento inteiramente casualizado para avaliação do GMD e DS dos cordeiros suplementados com os diferentes níveis de CAGM. Os dados de GMD e DS foram avaliados por análise de regressão considerando $5 \%$ de significância. Os diferentes níveis de suplementação de CAGM influenciaram de maneira quadrática $(p<0,05)$ o GMD e DS de cordeiros terminados a pasto. O nível de suplementação de CAGM a 1,0\% do PC em cordeiros terminados a pasto no período da seca apresentou o melhor valor da receita total para carcaça quente de $\mathrm{R} \$ 9.585,00$. Foi observado que o nível de $0,0 \%$ de suplementação concentrada apresentou a menor despesa total no valor de R \$ 7.317,82 em relação aos demais níveis de suplementação. Verificou-se que o melhor valor de receita líquida/mês de $\mathrm{R} \$ 419,75$ foi obtido para cordeiros terminados a pasto suplementados com nível de $1,0 \%$ do PC de concentrado contendo CAGM. Desta maneira, conclui-se que os cordeiros terminados a pasto no período da seca poderão ser suplementados com o nível de $1,0 \%$ do PC de concentrado contendo CAGM o que melhora o GMD, reduz os DS além de apresentar a melhor receita líquida/mês para esta atividade.
\end{abstract}

Palavras-chave: Co-produto, custo operacional, dias de suplementação, receita líquida

\begin{abstract}
The objective was evaluate the levels of concentrate supplementation $(0.0 \%, 0.5 \%, 1.0 \%$ and $1.5 \%$ of body weight - BW) consisting of cottonseed with ground corn (CSGC) in proportion $50 \%$ each in lambs finished on pasture (Grass Marandu) slaughtered at $31.7 \mathrm{~kg} \mathrm{BW}$, on average daily gain (ADG), days of supplementation (DS) and cost of production in the dry season. We used 20 lambs with initial BW $19 \pm 0.5 \mathrm{~kg}$ in four treatments. CSGC supplementation was provided in stalls separated by level of supplementation the eighteen hours daily. We used a completely randomized design to determine ADG and DS lambs supplemented with different levels of CSGC. The data of ADG and DS were evaluated
\end{abstract}

\footnotetext{
1 Profs. da Universidade do Estado de Mato Grosso, UNEMAT, Campus Universitário de Pontes e Lacerda, MT. E-mail: 1jgeron@ yahoo.com.br; aamex@hotmail.com; jo@unemat.br

2 Discente da UNEMAT, MT. E-mail: marcianozotec@hotmail.com

3 Prof ${ }^{\text {a }}$ da Universidade Estadual de Maringá, Campus de Maringá, PR. E-mail: 1mzeoula@uem.br

* Autor para correspondência
} 
by regression analysis considering 5\% significance. The different levels of supplementation CSGC influenced quadratic $(\mathrm{p}<0.05) \mathrm{ADG}$ and DS lambs on pasture. The level of supplementation CSGC to $1.0 \% \mathrm{BW}$ in lambs finished at pasture in the dry season had the best value of total lucre for the warm carcass of U\$ 9,585.00. It was observed that the level of $0.0 \% \mathrm{BW}$ of concentrate supplementation had the lesser total expenditure amounting to U\$ 7,317.82 in relation to other levels of supplementation. It was found that best value of net revenue per month the of U\$ 419.75 was obtained for lambs finished on pasture supplemented with a level of $1.0 \% \mathrm{BW}$ of concentrate containing CSGC. Thus, conclude that lambs finished at pasture can be supplemented with the level of $1.0 \%$ BW of CSGC which improves $\mathrm{ADG}$, reduces the DS beyond present the lucre best net /month for this activity.

Key words: By-product, operating cost, days supplementation, lucre net

\section{Introdução}

No Brasil, verifica-se, nos últimos anos, um aumento significativo na demanda de carne ovina, principalmente nos grandes centros urbanos. Tal constatação tem impulsionado a produção de cordeiros para abate, provocando a expansão da ovinocultura.

Segundo França (2006), a comparação da produção mundial de ovinos com a nacional indicou que o Brasil apresenta uma parcela muito pequena, mas com grande potencial para expansão da atividade, devido, principalmente, à vastidão do território brasileiro com grande produção de forragens além de ser um dos maiores produtores mundiais de grãos.

De acordo com estudo realizado por Carvalho et al. (2006), a atividade da ovinocultura no Brasil se caracteriza pela produção de carne, o que leva os produtores de ovinos a buscarem melhores resultados na produção de carne considerando a qualidade da mesma, assim os produtores deverão se preocupar com a nutrição e sanidade dos rebanhos de ovinos, buscando implantar e utilizar sistemas de produção tecnificados com a utilização de confinamentos e da suplementação concentrada.

O acréscimo de novas tecnologias no sistema de produção animal representa um custo adicional por unidade produzida e a utilização adequada dessas tecnologias pode gerar bons resultados biológicos e amortizar os custos fixos, aumentando a lucratividade da propriedade, além disso, em muitos casos, os resultados obtidos não cobrem os custos (fixos e variáveis), devido à má escolha da tecnologia a ser utilizada e/ou por sua utilização ineficiente (PILAU; ROCHA; SANTOS, 2003).

Para que a produção de cordeiros seja economicamente viável, torna-se necessário proporcionar ao animal condições de manifestar o máximo desempenho de suas potencialidades através do fornecimento de alimentação adequada e de baixo custo, a fim de alcançar as condições de peso ao abate o mais precocemente possível (SANTELLO et al., 2006).

A produção de carne ovina é uma excelente alternativa econômica para pequenos e médios produtores em função de sua nobreza e qualidade, entretanto, para maximizar sua produção com baixo custo é necessário fazer uso dos co-produtos da agroindústria. $\mathrm{O}$ estado de Mato Grosso é o maior produtor de algodão e soja além de se destacar como grande produtor de milho (IBGE, 2007), em consequência deste destaque a produção de co-produtos agroindustriais no estado torna-se abundante.

A melhoria do nível nutricional pode proporcionar aumento no custo de produção, o que pode tornar a atividade menos rentável, portanto, o consumo, o ganho médio diário e o rendimento de carcaça, são importantes parâmetros na avaliação do desempenho animal e da viabilidade econômica na ovinocultura (FERREIRA et al., 1998).

A utilização de dietas para cordeiros ricas em energia e proteína melhora a eficiência de ganho médio diário e a qualidade da carcaça (PESCE, 
2008). Historicamente o grão de milho é a principal fonte de energia utilizada na suplementação e no confinamento de animais ruminantes. No entanto, a utilização de grãos em excesso pode causar problemas digestivos e metabólicos nos ruminantes (NUNES, 1998). Por outro lado, a inclusão de gorduras na dieta promove aumento da densidade energética além de modificar a forma química da energia metabolizável, reduzindo a matéria orgânica fermentável no rúmen (PALMQUIST; WEISBJERG; HVELPLUND, 1993). As gorduras são compostos mais energéticos que os carboidratos e as proteínas, além disso a maior parte de sua absorção ocorre pós rúmen (JENKINS, 1993).

O caroço de algodão é um co-produto da indústria têxtil muito utilizado na alimentação de ruminantes por apresentar alta concentração de óleo, proteína e fibras (PESCE, 2008), além de conseguir reunir estes nutrientes em altas concentrações e possuir uma fibra de alta degradabilidade (HARVATINE et al., 2002). Este co-produto é oriundo do beneficiamento do algodão o qual visa à separação da fibra (pluma), sendo constituído pelo línter, a casca e a amêndoa.

Segundo Ezequiel (2001), o caroço de algodão pode ser definido como concentrado devido ao alto teor de energia e proteína. Entretanto, sua fibra é tão efetiva no rúmen quanto a de forragens.

O aumento do teor de energia das dietas através da adição de gorduras tem sido uma prática bastante utilizada, com produtos de origem vegetal (SILVA, 2005). De acordo com Palmquist (1984), a importância da gordura, ou de alimentos com alto teor de gordura na produção de animais ruminantes tende a receber menor ênfase do que outros nutrientes como proteína, fibra, minerais e vitaminas. Entretanto, a gordura possui importantes qualidades para as dietas por ser uma fonte densa de energia, aumentando a absorção de vitaminas lipossolúveis e de ácidos graxos essenciais, que atuam na regulação do metabolismo e aumenta a eficiência dos animais (PALMQUIST; MATTOS, 2006).
Devido à anatomia do aparelho digestivo dos ruminantes, estes são menos tolerantes a dietas contendo altos teores de lipídeos quando comparados aos monogástricos. Quando o nível de lipídios excede de $6 \%$ a $7 \%$ da dieta, podem ocorrer distúrbios digestivos como a diarréia e também decrescente consumo de matéria seca, pois os altos teores de ácidos graxos insaturados não esterificados (livres) provocam interferências no processo digestivo por revestir o conteúdo ruminal, impedindo a aderência das bactérias e o acesso das enzimas fibrolíticas na degradação das fibras, e devido a um efeito tóxico dos ácidos graxos insaturados sobre as células bacterianas (KOZLOSKI, 2002; TEIXEIRA; BORGES, 2005).

Os grãos de oleaginosas são menos prejudiciais a digestão da fibra do que a gordura ou óleos livres, pois propiciam o fornecimento de lipídeos através da liberação lenta da fração lipídica ao decorrer do dia, devido à regurgitação e ruminação das sementes (PESCE, 2008).

O custo operacional por quilograma de carcaça de cordeiras produzido em sistema de confinamento e de suplementação a pasto foi avaliado por Santello et al. (2006), estes autores observaram que o custo operacional de cordeiras terminadas a pasto recebendo suplementação concentrada foi menor em relação ao animais terminados em confinamento. Assim, os autores recomendaram a terminação de cordeiras em sistema de pastagem com suplementação concentrada.

O custo de produção de cordeiros alimentados com diferentes níveis protéicos de 12\%,16\%,20\% e $24 \%$ de PB foi verificado por Zundt et al. (2002), estes autores observaram que a margem de receita líquida foi decrescente, à medida que se elevou o teor de proteína na dieta. Este fato é reflexo da razão custo/benefício no acréscimo de proteína bruta na dieta, no qual a proteína é o nutriente mais caro da ração.

Na comparação do farelo de soja com o caroço de algodão, este último apresenta baixo custo, além de 
apresentar característica de um suplemento protéico e energético, disponível em grandes quantidades nas regiões produtoras de algodão principalmente no Estado de Mato Grosso (GERON, 2007).

Desta maneira, objetivou-se avaliar a viabilidade econômica da produção de cordeiros produzidos a pasto no período da seca suplementados com diferentes níveis $(0,0 \% ; 0,5 \% ; 1,0 \%$ e $1,5 \%$ do peso corporal - PC) de concentrado constituído de caroço de algodão com grão de milho moído (CAGM) na proporção de $50 \%$ cada, respectivamente.

\section{Material e Métodos}

O experimento foi conduzido no Laboratório de Análise de Alimentos e Nutrição Animal (LAANA) pertencente ao Departamento de Zootecnia da Universidade do Estado de Mato Grosso (UNEMAT) na fazenda "Pau D'alho" localizadas no município de Pontes e Lacerda - MT.

Foram utilizados 20 cordeiros machos, desmamados, sem raça definida, com peso corporal (PC) médio de $19 \pm 0,5 \mathrm{~kg}$, alojados em um piquete de Brachiaria brizantha cv. Marandu com 2,5 hectares (ha), até atingirem o peso corporal (PC) de abate de aproximadamente $31,7 \mathrm{~kg}$.

A disponibilidade de forragem foi estimada a cada 30 dias utilizando-se o método de dupla amostragem (WILM; COSTELO; KLIPPLE, 1944). Foram colhidas dez amostras no piquete a cada 30 dias, cortadas $5 \mathrm{~cm}$ do nível do solo, pesadas e secas em estufa com ventilação forçada a $55^{\circ} \mathrm{C}$. Considerando os valores das amostras cortadas (10) e estimadas visualmente (20), efetuou-se o cálculo da quantidade de MS, em kg/ha/mês, utilizando-se a equação proposta por Gardner (1986).

Após fracionar a forragem coletada na dupla amostragem em subamostras (aproximadamente $50 \%$ do material), separaram-se as proporções da planta em lamina foliar, pseudocolmos e material senescente. Obteve-se disponibilidade média de
$1.322 \mathrm{~kg}$ de $\mathrm{MS} / \mathrm{ha} / \mathrm{mês}$ no período de julho a novembro de 2008, composta de 54\% de lamina foliar, $35 \%$ de pseudocolmos e $11 \%$ de material senescente.

Os cordeiros permaneceram na mesma pastagem no período diurno durante a execução do experimento (julho a novembro de 2008), sendo alojados em instalações cobertas no período noturno, para proteção contra predadores, tendo disponível no cocho os seguintes níveis de suplementação concentrada constituída de caroço de algodão com grão de milho moído (CAGM) de 0,0\%, 0,5\%, 1,0\% e $1,5 \%$ do PC.

O suplemento concentrado construído de CAGM foi calculado para apresentar um teor médio de proteína bruta de $15,0 \%$ e nutrientes digestíveis totais de 85,0\% (NRC, 1985), sendo fornecido somente no fim da tarde, após os cordeiros serem levados para a instalação. A proporção utilizada de caroço de algodão e grão de milho moído para formulação do concentrado foi de $50 \%$ cada, respectivamente. A composição química dos alimentos está demonstrada na Tabela 1 , e a composição percentual e química do suplemento concentrado constituído de CAGM está apresentada na Tabela 2.

Para a determinação do desempenho animal, os cordeiros foram pesados antes de iniciar o período experimental e a cada 15 dias para obtenção dos dados de ganho médio diário (GMD) e ajuste do fornecimento da suplementação de CAGM $(0,0 \%$, $0,5 \%, 1,0 \%$ e $1,5 \%$ do PC). Foi adotado o método de lotação contínua, com carga fixa no piquete (PRUHMANN et al., 2004).

As coletas de amostras do caroço de algodão e grão de milho moído foram realizadas no início, meio e fim do experimento, essas amostras foram moídas em moinho tipo martelo com peneira com crivos de $1 \mathrm{~mm}$, para não descaracterizar a sua composição química. 
Tabela 1. Composição química da Brachiaria brizantha cv. Marandu (planta inteira e lamina foliar) durante os meses de julho a novembro de 2008 e do suplemento concentrado constituído de caroço de algodão e grão de milho moído.

\begin{tabular}{|c|c|c|c|c|c|c|c|c|}
\hline \multirow[t]{2}{*}{ Alimentos } & \multirow[t]{2}{*}{$\% \mathrm{MS}$} & \multicolumn{7}{|c|}{ Nutrientes expressos em $\%$ da MS } \\
\hline & & $\% \mathrm{MO}$ & $\% \mathrm{~PB}$ & $\% \mathrm{EE}$ & $\% \mathrm{FDN}$ & $\%$ FDA & $\% \mathrm{MM}$ & $\% \mathrm{NDT}^{1}$ \\
\hline \multicolumn{9}{|c|}{ Alimento volumoso } \\
\hline $\begin{array}{l}\text { Capim Marandu } \\
\text { (Planta inteira) }\end{array}$ & 59,37 & 91,24 & 3,52 & 1,07 & 72,41 & 43,85 & 8,75 & 49,53 \\
\hline $\begin{array}{l}\text { Capim Marandu } \\
\text { (lamina foliar) }\end{array}$ & 61,59 & 92,16 & 5,42 & 1,15 & 65,60 & 41,48 & 7,84 & - \\
\hline \multicolumn{9}{|c|}{ Suplemento concentrado } \\
\hline Caroço de algodão & 90,28 & 96,20 & 20,63 & 17,02 & 69,24 & 38,60 & 3,80 & 81,92 \\
\hline Grão de milho moído & 87,56 & 98,83 & 9,34 & 5,30 & 14,01 & 5,92 & 1,17 & 87,24 \\
\hline
\end{tabular}

MS: matéria seca; MO: matéria orgânica; PB: proteína bruta; EE: extrato etéreo; FDN: fibra em detergente neutro; FDA: fibra em detergente ácido; MM: matéria mineral. ${ }^{1}$ Valores estimados segundo recomendação de Valadares Filho et al. (2006).

Fonte: Elaboração dos autores.

Tabela 2. Composição percentual e química do suplemento concentrado (caroço de algodão com grão de milho moído).

\begin{tabular}{lc}
\hline Alimentos & Composição percentual do suplemento concentrado \\
\hline Caroço de algodão & 50 \\
Milho grão moído & 50 \\
Total & 100 \\
\hline Nutrientes & Composição química do suplemento concentrado \\
$\% \mathrm{MS}$ & 88,92 \\
$\% \mathrm{MO}^{1}$ & 97,51 \\
$\% \mathrm{~PB}^{1}$ & 14,98 \\
$\% \mathrm{EE}^{1}$ & 11,16 \\
$\% \mathrm{FDN}^{1}$ & 41,63 \\
$\% \mathrm{FDA}^{1}$ & 22,26 \\
$\% \mathrm{MM}^{1}$ & 2,49 \\
$\% \mathrm{NDT}^{1}$ & 84,58 \\
\hline
\end{tabular}

${ }^{1}$ Nutrientes expresso na matéria seca; MS: matéria seca; MO: matéria orgânica; PB: proteína bruta; EE: extrato etéreo; FDN: fibra em detergente neutro; FDA: fibra em detergente ácido e MM: matéria mineral.

Fonte: Elaboração dos autores.

As amostras de pasto, caroço de algodão, grão de milho moído e sobras do suplemento concentrado foram avaliadas quanto aos teores de matéria seca (MS), matéria orgânica (MO), matéria mineral $(\mathrm{MM})$, proteína bruta $(\mathrm{PB})$, extrato etéreo (EE), segundo as recomendações descritas por Silva e Queiroz (2002). Para a determinação da fibra em detergente neutro (FDN) e da fibra em detergente ácido (FDA) foram utilizadas a metodologia descrita por Van Soest, Robertson e Lewis (1991).

Para efetuar a análise do custo operacional por carcaça e por quilograma de carcaça do experimento, foram considerados o preço de mercado dos ingredientes do suplemento (caroço de algodão e grão de milho moído - CAGM) e o valor pago na região pela carcaça de cordeiros de acordo com as recomendações de Santello et al. (2006).

O custo dos alimentos concentrados foi calculado com dados de insumos e frete utilizados para a sua aquisição. Ressalta-se que todos os valores foram obtidos no ano de 2008 e no local em que se conduziu este estudo, município de Pontes e Lacerda - MT. O custo do grão de milho foi de $\mathrm{R} \$ 340,00$ a tonelada e do caroço de algodão foi 
$\mathrm{R} \$$ de 380,00 . Desta forma, o custo do suplemento concentrado (CAGM) foi de $\mathrm{R} \$ 0,36 / \mathrm{kg}$.

A planilha de cálculo da viabilidade econômica foi montada com dados coletados no experimento, referentes a 20 cordeiros terminados a pasto suplementados com diferentes níveis de CAGM. Entretanto, para que os resultados pudessem ser comparados, considerou-se módulo de 100 cordeiros/tratamento para realização dos cálculos de viabilidade econômica segundo Santello et al. (2006).

A determinação do custo de implantação e condução do sistema de suplementação foi realizada por meio do método da circular informativa da Fundação ABC (2003). Foi calculado o custo de produção de cordeiros a pasto baseado no valor do arrendamento de um hectare (ha) por mês para a capacidade de suporte $450 \mathrm{~kg} / \mathrm{ha}$. O valor de arrendamento no período de execução do estudo foi de R \$ 35,00/ha/mês. O valor de arrendamento para cada tratamento foi obtido de forma proporcional considerando o PC médio dos cordeiros no modulo de 100 animais em cada tratamento durante o período de avaliação (julho a novembro de 2008) para dos diferentes níveis de suplementação de CAGM.

O fornecimento de sal mineral foi de $5 \mathrm{~g} /$ dia/cordeiro e o seu custo foi de $\mathrm{R} \$ 1,50 / \mathrm{kg}$. O consumo de sal mineral foi estimado para o modulo de 100 animais para cada nível de suplementação de CAGM, o qual foi de $500 \mathrm{~g} / \mathrm{dia}$, este valor foi multiplicado pelo período de suplementação que os cordeiros tiveram até o abate em cada tratamento.

A infecção por endoparasitos foi acompanhada pela contagem de ovos por grama de fezes (OPG), sendo os cordeiros everminados nos casos de contagens superiores a 500 OPG. O custo com a everminação foi calculado baseado no custo do princípio ativo (ivermectina ${ }^{\circledR}$ ), o qual foi ministrado na dose de $0,5 \mathrm{~mL}$ para cada $25 \mathrm{~kg}$ de $\mathrm{PC}$, no valor de $\mathrm{R} \$ 0,07$ para cada $0,5 \mathrm{~mL} /$ cordeiro. $\mathrm{O}$ vermífugo foi administrado conforme a necessidade mensal dos cordeiros por meio da contagem de OPG, e convertida para o modulo de 100 animais/ tratamento.

O custo com mão-de-obra foi baseado no valor da diária vigente no período de julho a novembro de 2008, na região de Pontes e Lacerda - MT de $\mathrm{R} \$ 15,00$ para o desenvolvimento da atividade com 400 cordeiros, ou seja, foi utilizado um valor de 2 horas/dia de mão-de-obra para desenvolvimento da atividade para cada 100 cordeiros ( $\mathrm{R} \$ 3,75)$. Foi considerado para o cálculo de custo total de mãode-obra a multiplicação do custo das duas horas/ dia/tratamento pelo tempo médio que os cordeiros demoraram à atingir o peso de abate, ou seja, os dias de suplementação concentrada para cada tratamento.

Foi calculado o custo da aquisição dos cordeiros considerando o PC inicial para o modulo de 100 cordeiros/tratamento. O custo da compra dos cordeiros foi de $\mathrm{R} \$ 3,20 / \mathrm{kg}$ de PC, este valor estava vigente no período de execução do presente estudo.

A determinação do valor de despesa total para os diferentes níveis de suplementação de CAGM foi obtida pela soma de custo de arrendamento (equivalentes a quantidade de animais/ha/mês), compra de cordeiros, suplementação concentrada, everminação, mineralização e mão-de-obra segundo Santello et al. (2006).

Após o abate e a evisceração dos cordeiros, as carcaças foram pesadas (peso da carcaça quente), mantidas durante duas horas em temperatura ambiente e posteriormente transferidas para câmara frigorífica a $4^{\circ} \mathrm{C}$, onde permaneceram por 24 horas penduradas pelos tendões em ganchos apropriados, para manutenção das articulações tarsometatarsianas distanciadas a $17 \mathrm{~cm}$. Após este período, as carcaças (resfriadas) foram novamente pesadas para obtenção do peso da carcaça fria. A determinação do peso da carcaça quente e carcaça fria foram realizadas por meio de balança digital com capacidade de $15 \mathrm{~kg} \pm$ $0,2 \mathrm{~g}$ da marca Filizola ${ }^{\circledR}$.

As carcaças de cordeiros foram comercializadas na região de Pontes e Lacerda-MT e o valor de 
venda da carcaça quente e/ou fria foram de $\mathrm{R} \$ 7,50$ no final do ano de 2008.

Foi utilizado delineamento inteiramente casualizado para determinação do ganho médio diário (GMD) e dias de suplementação (DS) para os diferentes níveis de suplementação de CAGM em cordeiros terminados a pasto. Os dados obtidos para o GMD e DS foram submetidos ANOVA utilizando o programa "Sistema de Análise Estatística e Genética - SAEG" (UNIVERSIDADE FEDERAL DE VIÇOSA, 1997), e as diferenças obtidas foram testadas utilizando análise de regressão a $5 \%$ de probabilidade.
Os dados de viabilidade econômica da produção de cordeiros suplementados com CAGM, não passaram por análise estatística, uma vez que a diferença econômica encontrada baseasse na maior lucratividade que atividade possa alcançar.

\section{Resultados e Discussão}

Os valores de consumo de matéria seca (CMS), peso corporal (PC) inicial, ao abate e médio, dias de suplementação (DS) e ganho médio diário (GMD) de cordeiros terminados a pasto suplementados com diferentes níveis de CAGM estão demonstrados na Tabela 3.

Tabela 3. Valores médios de consumo de matéria seca (CMS) do suplemento, peso corporal inicial (PCi), peso corporal ao abate (PCa), peso corporal médio (PCm), dias de suplementação até o abate (DS) e ganho médio diário (GMD) de cordeiros terminados a pasto suplementados com diferentes níveis de caroço de algodão com grão de milho moído em relação ao peso corporal.

\begin{tabular}{|c|c|c|c|c|c|c|c|c|c|}
\hline \multirow[t]{2}{*}{ Variáveis } & \multicolumn{4}{|c|}{$\begin{array}{l}\text { Níveis de suplementação concentrada em } \\
\text { relação ao peso corporal }\end{array}$} & \multirow[t]{2}{*}{$\mathrm{Rg}$} & \multicolumn{3}{|c|}{ Valor de P } & \multirow[t]{2}{*}{$\% \mathrm{CV}$} \\
\hline & $0,0 \%$ & $0,5 \%$ & $1,0 \%$ & $1,5 \%$ & & $\mathrm{~L}$ & $\mathrm{Q}$ & $\mathrm{C}$ & \\
\hline CMS do supl. g/dia & 0,00 & 120,00 & 260,00 & 169,00 & - & - & - & - & - \\
\hline PCi kg & 18,29 & 19,57 & 19,50 & 18,86 & NS & 0,669 & 0,268 & 0,348 & 11,81 \\
\hline PCa kg & 30,17 & 32,07 & 32,64 & 32,00 & NS & 0,080 & 0,056 & 0,152 & 5,62 \\
\hline $\mathrm{PCm} \mathrm{kg}$ & 24,23 & 25,82 & 26,07 & 25,43 & & - & - & - & - \\
\hline DS dia & 133,00 & 105,00 & 96,00 & 103,00 & 1 & 0,012 & 0,007 & 0,098 & 14,61 \\
\hline GMD g/dia & 90,00 & 119,00 & 137,00 & 128,00 & 2 & 0,010 & 0,001 & 0,169 & 11,26 \\
\hline
\end{tabular}

${ }^{1} \mathrm{Y}=133,128571-72,6000 \mathrm{X}+35,142857 \mathrm{X}^{2},\left(\mathrm{R}^{2}=99,94 \%\right)$;

${ }^{2} \mathrm{Y}=0,088921+0,083986 \mathrm{X}-0,038143 \mathrm{X}^{2}\left(\mathrm{R}^{2}=99,01 \%\right)$;

Rg: equação de regressão; L: equação linear; Q: equação quadrática; C: equação cúbica; \%CV: coeficiente de variação. Supl: suplemento. ${ }^{\text {NS: }}$ não significativo.

Fonte: Elaboração dos autores.

A suplementação concentrada contendo CAGM nos níveis de $0,0 \% ; 0,5 \% ; 1,0 \%$ e $1,5 \%$ do PC afetou $(\mathrm{P}<0,05)$ de forma quadrática o GMD ( $\mathrm{Y}=$ 133,128571-726000X+35,142857 $\mathrm{X}^{2}$ ) dos cordeiros em terminação (Tabela 3) e o melhor GMD foi observado com a suplementação de $1,0 \%$ do PC de CAGM.

Os diferentes teores de suplementação concentrada contendo CAGM influenciaram (P $<0,05)$ de maneira quadrática $(\mathrm{Y}=133,128571$ -
$726000 \mathrm{X}+35,142857 \mathrm{X}^{2}$ ) os DS de cordeiros terminados a pasto. Provavelmente este efeito foi devido o suplemento concentrado apresentar elevado teor de gordura (11,16\%), a qual foi diluída com o consumo de MS da pastagem e assim possibilitou um teor de gordura total da dieta abaixo da recomendação máxima de 7\% na dieta total, o que não prejudicar a digestão da fibra (VAN SOEST, 1994) além de apresentar elevado teor de NDT. Outro fator que pode ter interferido nos resultados obtidos para os DS e no GMD seria a seleção de 
alimentos concentrado no cocho realizada pelos cordeiros suplementados com $1,5 \%$ do PC, os quais provavelmente ingeriram maior quantidade de milho grão, o que pode ter refletido em modificação da fermentação ruminal com conseqüente redução do $\mathrm{pH}$ ruminal e da ingestão de MS.

Desta forma, o teor de $1,0 \%$ do PC de suplementação concentrada contendo CAGM em cordeiros terminados a pasto apresentou o maior GMD e maior consumo de MS do suplemento, consequentemente esses demoraram menos tempo para alcançarem o peso de abete de aproximadamente $31,7 \mathrm{~kg}$, em relação aos demais níveis de suplementação concentrada.

A análise econômica da produção de cordeiros terminados a pasto alimentados com diferentes níveis de suplementação concentrada contendo CAGM pode ser observada na Tabela 4.

O melhor valor de receita total da carcaça quente (CQ) e da carcaça fria (CF) foi observado para o nível de suplementação de CAGM a 1,0\% do PC, como media de $\mathrm{R} \$ 9.585,00$ e $\mathrm{R} \$ 9.360,00$, respectivamente.

A suplementação de CAGM a 1,5\% do PC para cordeiros terminados a pasto apresentou a menor receita total $(\mathrm{R} \$)$ para a CQ e CF em relação aos demais tratamentos. Provavelmente o teor de gordura do suplemento concentrado conciliado com uma disponibilidade elevada de MS do mesmo no cocho pode ter resultado em um efeito associativo negativo entre a suplementação concentrada e o consumo de forragem, conseqüentemente pode ter refletido no menor peso da $\mathrm{CQ}, \mathrm{CF}$ e na receita total deste tratamento.

A despesa total para a suplementação de cordeiros terminados a pasto apresentou menor valor (R\$ 7.317,82) para o nível de $0,0 \%$ de suplementação de CAGM em relação aos demais tratamentos com valor médio de $\mathrm{R} \$ 7.995,38$. Este maior valor de despesa total para os maiores níveis de suplementação era esperado, uma vez que há um aumento no fornecimento de alimentos concentrados, e esse apresentam um maior custo do que o pasto, isso implica em maior custo com alimentação. Entretanto, a despesa total sozinha não é um bom parâmetro de avaliação da viabilidade econômica da atividade, uma vez que o produtor deverá considerar os valores de receita total da CQ e os dias de suplementação sendo que este último interfere de forma direta no valor final da mão-deobra e no custo operacional.

Estudo realizado por Santello et al. (2006) para avaliar as características da carcaça e custo de produção de diferentes sistemas de produção de cordeiros, apresentou uma despesa total de $\mathrm{R} \$ 9.775,95$ para cordeiros terminados a pasto suplementados com $1,0 \%$ do PC deração concentrada para modulo de 100 animais/tratamento, valor inferior ao encontrado no presente estudo. Estes autores obtiveram valores próximos ao do presente estudo para o custo de suplementação de R $\$ 0,38 /$ $\mathrm{kg}$ de ração e arrendamento de $\mathrm{R} \$ 40,00 / \mathrm{ha} / \mathrm{mês}$, entretanto a forma de obtenção do custo da mão-deobra considerou apenas uma hora/dia de dedicação a atividade no valor de $\mathrm{R} \$ 1,87 /$ hora/dia e o total de dias de suplementação utilizado foi de 66 dias, o que pode ter contribuído para esta variação observada entre os estudos no valor de despesa total.

Entretanto o custo operacional $/ \mathrm{kg}$ de carcaça produzido no presente estudo foi superior aos obtidos por Macedo, Siqueira e Martins (2000), os quais avaliaram o sistema de terminação em pastagem e confinamento ( $\mathrm{R} \$ 2,26$ e $\mathrm{R} \$ 2,31$, respectivamente), porém, esses autores não consideraram o arrendamento da terra durante todo o período de terminação dos cordeiros a pasto. 
Tabela 4. Análise da viabilidade econômica da produção de cordeiros terminados a pasto suplementados com diferentes níveis concentrado em relação ao peso corporal constituído por caroço de algodão com grão de milho moído.

\begin{tabular}{|c|c|c|c|c|}
\hline \multirow[t]{2}{*}{ Variáveis } & \multicolumn{4}{|c|}{ Níveis de suplementação concertada em relação ao peso corporal } \\
\hline & $0,0 \%$ & $0,5 \%$ & $1,0 \%$ & $1,5 \%$ \\
\hline Peso das carcaças quente - CQ (kg) & 12,13 & 11,87 & 12,78 & 11,82 \\
\hline Peso das carcaças frias - CF (kg) & 11,50 & 11,57 & 12,48 & 11,35 \\
\hline Mortalidade (\%) & 0,0 & 0,0 & 0,0 & 0,0 \\
\hline Numero de animais abatidos & 100 & 100 & 100 & 100 \\
\hline Total carcaça quente $(\mathrm{kg})$ & $1.213,00$ & $1.187,00$ & $1.278,00$ & $1.182,00$ \\
\hline Total carcaça fria $(\mathrm{kg})$ & $1.150,00$ & $1.157,00$ & $1.248,00$ & $1.135,00$ \\
\hline Valor de comercialização CQ e CF (R\$/kg) & 7,50 & 7,50 & 7,50 & 7,50 \\
\hline Receita total CQ $(\mathrm{R} \$)$ & $9.097,50$ & $8.902,50$ & $9.585,00$ & $8.865,00$ \\
\hline Receita total CF (R\$) & $8.625,00$ & $8.677,50$ & $9.360,00$ & $8.512,50$ \\
\hline \multicolumn{5}{|l|}{ Despesas } \\
\hline Custo de arrendamento ha/mês/UA* (R\$) & 35,00 & 35,00 & 35,00 & 35,00 \\
\hline $\begin{array}{l}\text { A) Valor total de arrendamento em relação ao } \\
\text { total de PC médio dos cordeiros }\end{array}$ & 835,49 & 702,88 & 648,85 & 679,08 \\
\hline B) Compra de animais $(\mathrm{R} \$ 3,20 / \mathrm{kg})$ & $5.852,80$ & $6.262,40$ & $6.240,0$ & $6.035,20$ \\
\hline Consumo total do suplemento $(\mathrm{kg})$ & 0,00 & $1.260,00$ & $2.496,00$ & $1.740,70$ \\
\hline Custo da suplementação/kg (R\$) & 0,36 & 0,36 & 0,36 & 0,36 \\
\hline C) Custo da suplementação total ( $\mathrm{R} \$)$ & 0,00 & 453,60 & 898,56 & 626,65 \\
\hline D) Vermífugo & 31,03 & 24,50 & 22,40 & 24,03 \\
\hline Consumo total do sal mineral (kg) & 66,50 & 52,50 & 48,00 & 51,50 \\
\hline Custo do sal minerais/kg (R\$) & 1,50 & 1,50 & 1,50 & 1,50 \\
\hline E) Custo total do sal mineral (R\$) & 99,75 & 78,75 & 72,00 & 77,25 \\
\hline Custo da mão-de-obra (diária) $\mathrm{R} \$$ & 15,00 & 15,00 & 15,00 & 15,00 \\
\hline Custo da mão-de-obra 2h/dia R\$ & 3,75 & 3,75 & 3,75 & 3,75 \\
\hline Total de dias dedicado a atividade & 133 & 105 & 96 & 103 \\
\hline Total de meses de suplementação até o abate & 4,43 & 3,50 & 3,20 & 3,43 \\
\hline F) custo total com mão-de-obra & 498,75 & 393,75 & 360,00 & 366,35 \\
\hline Despesa total $(\mathrm{R} \$)(A+B+C+D+E+F)$ & $7.317,82$ & $7.915,88$ & $8.241,81$ & $7.828,46$ \\
\hline Custo operacional por carcaça $(\mathrm{R} \$)$ & 73,18 & 79,16 & 82,42 & 78,28 \\
\hline Custo operacional/kg de carcaça (R\$) & 6,03 & 6,67 & 6,45 & 6,62 \\
\hline Receita/kg de carcaça & 1,47 & 0,83 & 1,05 & 0,88 \\
\hline Receita líquida Total R\$ & $1.779,68$ & 986,62 & $1.343,19$ & $1.036,54$ \\
\hline Receita líquida por mês $(\mathrm{R} \$)$ & 401,43 & 281,89 & 419,75 & 301,90 \\
\hline Receita líquida por ano (R\$) & $4.817,16$ & $3.382,68$ & $5.037,00$ & $3.622,80$ \\
\hline
\end{tabular}

* ha: hectare; UA: unidade animal de $450 \mathrm{~kg}$ de PC/ha; PC: peso corporal; CQ: carcaça quente; $\mathrm{CF}$ : carcaça fria. $A+B+C+D+E+F$ : são os item utilizados para o cálculo da despesa total em reais. R\$: reais.

Fonte: Elaboração dos autores.

O custo operacional da carcaça de cordeiros suplementos com CAGM a $0,0 \%$ do PC foi de R\$ $73,18$, este valor foi menor ( $\mathrm{R} \$ 9,24)$ em relação os cordeiros suplementados com $1,0 \%$ do PC de R\$ 82,42, Porém, foi observado que este valor do custo operacional por carcaça foi amortizado pelo peso da carcaça quente produzida nos diferentes níveis de suplementação concentrada. Desta forma, o custo operacional $/ \mathrm{kg}$ de carcaça para os cordeiros suplementados com $0,0 \%$ do PC foi de R\$ 6,03 e os suplementados com $1,0 \%$ do PC foi de R\$ 6,45 (Tabela 4). Provavelmente esta amortização no valor do custo operacional $/ \mathrm{kg}$ de carcaça tenha ocorrido em virtude de um maior $(p<0,05)$ GMD 
dos cordeiros que receberam suplemento de CAGM a 1,0\% do PC em relação aos demais tratamentos (Tabela 3).

Foi verificado que o custo operacional $/ \mathrm{kg}$ de carcaça de $\mathrm{R} \$ 6,45$ para cordeiros suplementado com concentrado a 1,0\% do PC na região Sudoeste de Mato Grosso foi 10,85\% menor em relação aos cordeiros suplementados com concentrado a 1,0\% do PC no Sul do Brasil (SANTELLO et al., 2006) com custo operacional de $\mathrm{R} \$ 7,15 / \mathrm{kg}$ de carcaça. Esta observação demonstra que a ovinocultura praticada na região Centro-Oeste do país pode ser um alternativa sustentável para a diversificação das atividades desenvolvidas dentro das pequenas e medias propriedades, uma vez que os cordeiros produzidos nesta região possuem um menor custo operacional $/ \mathrm{kg}$ de carcaça em relação a região Sul do país.

Foi observada uma diferença de $\mathrm{R} \$ 0,42$ no valor da receita/ $\mathrm{kg}$ de carcaça entre o nível de $0,0 \%$ de suplementação concentrada em relação ao nível de suplantação de 1,0\% do PC. Entretanto, a maior eficiência econômica da atividade da ovinocultura não esta atrelado apenas a receita/kg de carcaça e sim a toda cadeia produtiva dentro da propriedade onde deve ser considerada a conservação e a manutenção da pastagem no período da seca e os dias de suplementação até o abate, uma vez que este último interfere de forma direta no custo operacional e conseqüentemente na receita líquida/mês.

Os resultados obtidos para a receita $/ \mathrm{kg}$ de carcaça encontrados neste experimento foram maiores que os obtidos por Vasconcelos, Sousa e Barros (2002), estes autores trabalharam com cordeiros sem raça definida em pastagem nativa e capim - Tanzânia, com carga variável de 40 e 60 animais/ha, com receita/kg de carcaça de $\mathrm{R} \$ 0,07$ e R $\$ 0,21$, respectivamente enquanto no presente trabalho os valores variaram de $\mathrm{R} \$ 0,83$ a $1,47 / \mathrm{kg}$ de carcaça (Tabela 4).

A análise da viabilidade econômica realizada por Santello et al. (2006) para ovinos abatidos com $30 \mathrm{~kg}$ de $\mathrm{PC}$ terminados a pasto recebendo $1,0 \%$ de suplementação concentrada, apresentou custo operacional $/ \mathrm{kg}$ de carcaça de $\mathrm{R} \$ 7,15$. Estes autores verificaram que a receita $/ \mathrm{kg}$ de carcaça de cordeiros suplementados com 1,0\% do PC de ração concentrada foi de $\mathrm{R} \$ 2,35$, este valor é 55,31\% superior ao encontrado no presente estudo. Este fato provavelmente ocorreu devido ao valor de comercialização da carcaça de cordeiros praticado no Sul do Brasil ser de R 9,50/kg e o valor de comercialização no município de Pontes e Lacerda - MT de R\$ 7,50/kg alem disso a quantidade de horas trabalhada considerada em cada estudo para obtenção do custo total de mão-de-obra pode ter contribuído para esta variação.

A receita líquida total $(\mathrm{R} \$)$ apresentou o melhor valor para o nível de $0,0 \%$ do PC de suplementação concentrada contendo CAGM em cordeiros terminados a pasto com um montante de $\mathrm{R} \$ 1.779,68$. Este valor de receita total (R\$) foi $24,52 \%$ superior em relação ao nível de 1,0\% de suplementação (R\$ $1.343,19)$. Estes valores de receita total ficaram abaixo do observado por Santello et al. (2006) para cordeiros suplementados com ração concentrada a $1,0 \%$ do PC, com um valor médio de $\mathrm{R} \$ 3.210,55$ para modulo de 100 animais.

Entretanto há necessidade de padronizar a receita líquida total em uma unidade comum para os diferentes níveis de suplementação em relação ao total de dias de suplementação até o abate. Desta forma, a receita líquida foi expressa por mês para os diferentes tratamentos. Foi observado que o nível de 1,0\% de suplementação constituída de CAGM apresentou o maior valor de receita líquida/mês de $\mathrm{R} \$ 419,75$, este valor foi $4,36 \%$ superior ao nível de 0,0 de suplementação com CAGM em cordeiros terminados a pasto. Este variação no valor de receita líquida/mês provavelmente pode ter ocorrido em função dos cordeiros terminados a pasto suplementados com $1,0 \%$ do PC terem permanecido um menor tempo no sistema de produção devido ao maior GMD o que refletiu em um menor custo com mão-de-obra e maior eficiência de utilização do sistema de produção. 
Desta maneira, conclui-se que a suplementação de $1,0 \%$ do peso corporal de concentrado constituído de caroço de algodão com grão de milho na proporção de $50 \%$ cada em cordeiros terminados a pasto no período da seca melhora o ganho médio diário, reduz os dias de suplementação e apresenta uma maior viabilidade econômica, com uma maior receita líquida por mês.

\section{Agradecimentos}

A Fundação de Amparo à Pesquisa do Estado de Mato Grosso (FAPEMAT) por financiado o presente estudo e ter concedido bolsas de iniciação cientifica aos acadêmicos do Curso de Zootecnia. A Universidade do Estado de Mato Grosso (UNEMAT) - Campus de Universitário de Pontes e Lacerda, por ter apoiado e auxiliado no desenvolvimento desta pesquisa cedendo as instalações e equipamentos do Laboratório de Análise de Alimentos e Nutrição Animal (LAANA). Ao senhor e senhora Bragatto por ter fornecido as instalações e animais da fazenda Pau D'Alho para a execução do presente estudo.

\section{Referências}

CARVALHO, S.; BROCHIER, M.; CAPPELATTI, L.; PIVATO. J. Avaliação econômica de três sistemas alimentares utilizados na terminação de cordeiros. Archivos Latinoamericanos de Produccion Animal, Maracaibo,Venezuela, v. 14, n. 3, p. 86-87, 2006.

EZEQUIEL, J. M. B. Uso de caroço de algodão na alimentação animal. In: SIMPÓSIO GOIÃO SOBRE MANEJO E NUTRIÇÃO DE BOVINOS, 3., 2001, Goiânia. Anais... Goiânia: Colégio Brasileiro de Nutrição Animal (CBNA), 2001, p. 92-99.

FERREIRA, M. A.; VALADARES FILHO, S. C.; COELHO DA SILVA, J. F.; PAULINO, M. F.; VALADARES, R, F. D.; CECON, P. R.; MUNIZ, E. B. Consumo, Conversão alimentar, ganho de peso e características de carcaça de bovinos F1 Simental e Nelore. Revista Brasileira de Zootecnia, Viçosa, MG, v. 28, n. 2, p. 343-351, 1998.

FRANÇA, P. M. Nivveis de energia metabolizável na dieta de cordeiros Santa Inês e sua influência na composição química da carcaça e seus cortes. 2006. Dissertação
(Mestrado em Zootecnia) - Universidade Federal de Lavras, Minas Gerais.

FUNDAÇÃO ABC. Informativo para assistência e divulgação técnica agropecuário. Castro: Holambra, $\mathrm{n}$. 21, 2003. $32 \mathrm{p}$.

GARDNER, A. L. Técnicas de pesquisa em pastagem e aplicabilidade de resultados em sistema de produção. Brasília: IICA/EMBRAPA 3/4 CNPGL, 1986. 197 p.

GERON, L. J. V. Utilização de resíduos agroindustriais na alimentação de animais de produção. Publicações em Medicina Veterinária e Zootecnia - Pubvet, Londrina, v. 1, n. 9, p. 110-125, 2007.

HARVATINE, D. I.; WINKLER, J. E.; DEVANTGUILLE, M.; FIRKINS, J. L.; ST-PIERRE, N. R.; OLDICK, B. S.; EASTRIDGE, M. L. Whole linted cottonseed as a forage substitute: fiber effectiveness and digestion kinetics. Journal of Dairy Science, Champaign, v. 86, n. 6, p. 1988-1999, 2002.

INSTITUTO BRASILEIRO DE GEOGRAFIA E ESTATISTICA - IBGE. Produção agrícola municipal - cereais, leguminosas e oleaginosas. 2007. Disponível em: <http://www.ibge.gov.br/estadosat/temas.php? sigla $=\mathrm{mt} \&$ tema $=$ pamclo2007 $>$. Acesso em: 15 set. 2008 .

JENKINS, T. C. Lipid metabolism in the rúmen. Journal of Dairy Science, Champaign, v. 76, n. 11, p. 3851-3863, 1993.

KOZLOSKI, G. V. Bioquímica dos ruminantes. Santa Maria: UFSM, 2002. 140 p.

MACEDO, A. F. M.; SIQUEIRA, E. R.; MARTINS, N. E. Análise econômica da produção de carne de cordeiros sob dois sistemas de terminação: pastagem e confinamento. Ciência Rural, Santa Maria, v. 30, n. 4, p. 677-680, 2000.

NATIONAL RESEARCH COUNCIL - NRC. Nutrients requirements of sheep. 5. ed. Washington, D.C.: National Academy Press, 1985. 99 p.

NUNES, I. J. Nutrição animal básica. Belo Horizonte: IIto Jóse Nunes, 1998.

PALMQUIST, D. L. The feeding value of fat. In:

Use of fat in diets for lactating dairy cows. London: Butterworths, 1984, p. 293-311.

PALMQUIST, D. L.; MATTOS, W. R. S. Metabolismo de lipídeos. In: BERCHIELLI, T. T.; PIRES, A. V.; OLIVEIRA, S. G. Nutrição de ruminantes. Jaboticabal: Funep, 2006. p. 287-309.

PALMQUIST,D.L.;WEISBJERG,M.R.;HVELPLUND, T. Ruminal, intestinal and total digestibilites of nutrients i cows fed diets high in fat and undegradable protein. 
Journal of Dairy Science, Champaign, v. 76, n. 9, p. 1353-1364, 1993.

PESCE, D. M. C. Efeito da dieta contendo caroço de algodão no desempenho, características quantitativas da carcaça e qualitativas da carne de novilhos Nelore confinados. 2008. Tese (Doutorado em Zootecnia) Faculdade de Zootecnia e Engenharia de Alimentos, Universidade de São Paulo, Pirassununga.

PILAU, A.; ROCHA, M. G.; SANTOS, D. T. Análise econômica de sistemas de produção para recria de bezerras de corte. Revista Brasileira de Zootecnia, Viçosa, MG, v. 32, n. 4, p. 966-976, 2003.

PRUHMANN, P. E. F.; BRANCO, A. F.; CECATO, U.; JOBIM, C. C.; GUIMARÃES, K. C.; FERREIRA, R. A. Suplementação de bovinos em pastagens de Coastcross (Cynodon dactylon L. Pers) no inverno. Revista Brasileira de Zootecnia, Viçosa, MG, v. 33, n. 4, p. 801-810, 2004.

SANTELlO, G. A.; MACEDO, F. A. F.; MEXIA, A. A.; SAKAGUTI, E. S.; DIAS, F. J.; PEREIRA, M. F. Característica de carcaça e análise do custo de sistemas de produção dde cordeiros $1 / 2$ Dorset Santa Inês. Revista Brasileira de Zootecnia, Viçosa, MG, v. 35, n. 4, p. 18521859, 2006.

SILVA, D. J.; QUEIROZ, A. C. Análise de alimentos (métodos químicos e biológicos. 2. ed. Viçosa, MG: UFV, 2002. $178 \mathrm{p}$.

SILVA, S. L. Milho grão seco, úmido e sais de cálcio de ácidos graxos em dietas para novilhos Nelore em confinamento: desempenho, característica de carcaça e perfil de ácidos graxos. 2005. Tese (Doutorado em Zootecnia) - Universidade de São Paulo, Pirassununga.

TEIXEIRA, D. B.; BORGES, I. Efeito do nível de caroço integral de algodão sobre o consumo e digestibilidade aparente da fração fibrosa do feno de braquiária (Brachiaria decumbens) em ovinos. Arquivo Brasileiro de Medicina Veterinária e Zootecnia, Belo Horizonte, v. 57, n. 2, p. 229-233, 2005.

UNIVERSIDADE FEDERAL DE VIÇOSA - UFV. Sistema de análises estatísticas e genéticas - SAEG. Viçosa: UFV. 1997. 150 p. (Manual do usuário).

VALADARES FILHO, S. C.; MAGALHÃES, K. A.; ROCHA JÚNIOR, V. R.; CAPELLE, E. R. Tabelas brasileiras de composição de alimentos para bovinos. 2 . ed. Viçosa: UFV, 2006. 329 p.

VAN SOEST, P. J.; ROBERTSON, J. B.; LEWIS, B. A. Methods for dietary fiber neutral detergent fiber, and nostarch polysaccharides in relation to animal nutrition. Journal of Dairy Science, Champaign, v. 74, n. 12, p. 3583-3597, 1991.

VAN SOEST, P. J. Nutritional ecology of the ruminant. 2. ed. New York: Cornell University, 1994.

VASCONCELOS, V. R.; SOUSA, F. B.; BARROS, N. $\mathrm{N}$. Rendimento de carcaça e peso de cortes comerciais de cordeiros terminados a pasto. In: REUNIÃO ANUAL DA SOCIEDADE BRASILEIRA DE ZOOTECNIA, 39., 2002, Recife. Anais... Recife: Sociedade Brasileira de Zootecnia, 2002. CD-ROM.

WILM, H. G.; COSTElO, O. F.; KLIPPLE, G. E. Estimating forage yield by the double sampling method. Journal American of Agronomic, Madson, v. 36, n. 1, p. 194-203, 1944.

ZUNDT, M.; MACEDO, F. A. F.; MARTINS, E. N.; MEXIA, A. A.; YAMAMOTO, S. M. Desempenho de cordeiros alimentados com diferentes níveis protéicos. Revista Brasileira de Zootecnia, Viçosa, MG, v. 31, n. 3, p. 1307-1314, 2002. 